\title{
Recombinant human vascular endothelial growth factor receptor 1 effectively inhibits angiogenesis in vivo
}

\author{
JINLIANG WANG ${ }^{1}$, MINGLEI SHI ${ }^{2}$, YONGYI XI ${ }^{2}$, LIHUA GAO ${ }^{2}$, GUANYI ZHANG ${ }^{2}$, \\ YONG SHAO $^{2}$, HUIPENG CHEN ${ }^{2}$ and XIANWEN HU ${ }^{2}$ \\ ${ }^{1}$ Department of General Oncology, Chinese PLA General Hospital, Beijing 100853; \\ ${ }^{2}$ Department of Cell Engineering, Beijing Institute of Biotechnology, Beijing 100071, P.R. China
}

Received July 11, 2013; Accepted May 30, 2014

DOI: $10.3892 / \mathrm{mmr} .2015 .3229$

\begin{abstract}
Vascular endothelial growth factor (VEGF) plays an important role in both physiological and pathological angiogenesis. VEGF receptor-1 (VEGFR-1) acts as a decoy VEGF receptor that enables the regulation of VEGF on the vascular endothelium. In the present study, the recombinant human VEGFR1D1-3/Fc (rhVEGFR-1), which contains key domains for VEGF binding, was cloned and expressed in Chinese hamster ovary (CHO) cells. The rhVEGFR-1 protein was purified using protein-A affinity chromatography. The molecular weight of rhVEGFR-1 was found to be $\sim 162$ and $81 \mathrm{kD}$ in non-reducing and reducing SDS-PAGE, respectively. The majority of the final protein products were in the dimeric conformation. Western blot analysis revealed that rhVEGFR-1 was only capable of binding to the full glycan form of rhVEGF-165 and rhVEGF-121. The dissociation constant for the binding of rhVEGFR-1 to VEGF-165, detected using Biacore, was 285 pM. In addition, rhVEGFR-1 inhibited the proliferation and migration of human microvascular endothelial cells. In vivo experiments also demonstrated that rhVEGFR-1 inhibited chicken chorioallantoic membrane neovascularization and angiogenesis in nude mice. In conclusion, an anti-angiogenic recombinant soluble VEGFR was expressed (up to $5 \mathrm{mg} / \mathrm{l}$ ) in $\mathrm{CHO}$ cells and was shown to be capable of inhibiting neovascularization in vivo and in vitro.
\end{abstract}

\section{Introduction}

Vascular endothelial growth factor (VEGF), also known as vascular permeability factor, is an endothelial cell-specific mitogen and an angiogenic inducer (1). The activation of VEGF induces mitogenic permeability of the vascular endothelium; thus, VEGF has an important role in various physiological

Correspondence to: $\mathrm{Dr}$ Xianwen $\mathrm{Hu}$, Department of Cell Engineering, Beijing Institute of Biotechnology, 20 Dongdajie Street, Fengtai, Beijing 100071, P.R. China

E-mail: xianwenrhu@163.com

Key words: vascular endothelial growth factor, soluble vascular endothelial growth factor receptor, angiogenesis, anti-angiogenesis and pathological modulations, including cyclical blood vessel proliferation, longitudinal bone growth, endochondral bone formation, wound healing, cardiovascular diseases, ocular disorders, rheumatoid arthritis and psoriasis (2-4). Specifically, VEGF is a critical factor in tumor angiogenesis; VEGF is highly expressed in various tumorous tissues, and the activation of VEGF often promotes tumor growth (5). The VEGF family of proteins in mammals is encoded by five different genes: VEGFA, VEGFB, VEGFC, FIGF, and placenta growth factors (PGF-1 and PGF-2) (6). VEGFA has the most profound effects on stimulating endothelial cell proliferation, survival, and differentiation. Alternative splicing of the VEGFA gene yields five different isoforms: VEGFA-120, VEGFA-144, VEGFA-164, VEGFA-188, and VEGFA-205; each differing in biological activity, however they are primarily associated with angiogenesis (7-10). The VEGFA isoform regulates cell proliferation through two membrane-bound receptor tyrosine kinases, VEGFR1 and VEGFR2, which bind VEFGA with high affinity.

VEGF binds two related receptor tyrosine kinases (RTKs), VEGF receptor-1 (VEGFR-1) and VEGFR-2. VEGFR-1 and VEGFR-2 have similar extracellular and transmembrane domains containing a tyrosine kinase sequence $(11,12)$. A spliced, soluble form of VEGFR-1 (soluble Flt-1), once activated, leads to the inhibition of downstream pathways of VEGF. Since the binding site for VEGF (and placental growth factor) is primarily located in the immunoglobulin-like domain (13), it has been proposed that VEGFR-1 may not be a primary receptor, but a decoy receptor to prevent VEGF from binding to VEGFR-2 (14).

In the present study, a recombinant VEGFR-1 was constructed for expression in vitro and in vivo. The aim of this study was to examine the exact role of VEGFR-1 in regulating VEGF-induced angiogenesis.

\section{Materials and methods}

Generation ofrecombinanthuman VEGFR1 domains $(D) 1-3 / F C$ (rhVEGFR-1). cDNA (National Center for Biotechnology Information reference NM_002019.3) encoding the human VEGFR-1D1-3 was cloned using chemical synthesis and overlap extension polymerase chain reaction. The primers used were as follows: Forward, 5'-GGAATTCCGATATCA 
CCATGGTCAGCTACTGGGAC-3' and reverse, 5'-CGG GATCCCGACTTACCTGTTTTATCATATATATGCACTGA G-3'. The cDNA sequences were fused with a human immunoglobulin $\mathrm{G}(\mathrm{IgG}) 1 \mathrm{Fc}$ fragment with an intron included (provided by Dr H.Z. Liu, Beijing Institute of Basic Medical Sciences) and inserted into a cloning vector pcDNA3.1(+) (Invitrogen Life Technologies, Carlsbad, CA, USA), resulting in pcDNA3.1-rhVEGFR-1.

\section{Expression of rhVEGFR-1}

Cell transfection. The Chinese hamster ovary (CHO)-K1 cells were maintained at $37^{\circ} \mathrm{C}$ and under $5 \% \mathrm{CO}_{2}$ in Dulbecco's modified Eagle's medium (DMEM)/F12 (1:1) (HyClone, Logan, UT, USA) containing $10 \%$ fetal bovine serum (HyClone). The cells were transfected with pcDNA3.1-rhVEGFR-1 plasmid with Lipofectamine $^{\mathrm{TM}} 2000$ reagent (Invitrogen Life Technologies). The stable, higher-expression recombinant $\mathrm{CHO}$ (rCHO) cells were identified using ELISA (Fangcheng Biotechnology Company, Beijing, China).

$r C H O$ cell culture and purification of rhVEGFR-1. The selected $\mathrm{rCHO}$ cell line was cultured in roller bottles with DMEM/F12 (1:1) supplemented with 2\% newborn calf serum until the cells were $~ 90 \%$ confluent. The DMEM/F12 (1:1) was replaced every two days. rhVEGFR-1 was purified from the cell culture supernatant using rProtein A Sepharose ${ }^{\mathrm{TM}}$ Fast Flow (GE Healthcare Life Sciences, Pittsburgh, PA, USA) affinity chromatography. The supernatant was adjusted to $\mathrm{pH} 6.8$ in $20 \mathrm{mM} \mathrm{Na} \mathrm{HPO}_{4}$ and applied to protein A column (GE Healthcare Life Sciences) by ÄKTAprime plus (GE Healthcare Life Sciences), and rhVEGFR-1 protein was eluted using $0.5 \mathrm{M}$ arginine, $\mathrm{pH} 3.5(15,16)$. The eluted protein was neutralized immediately using $1 / 10$ volume of $1 \mathrm{M}$ Tris-HCl, $\mathrm{pH}$ 9.0.

\section{Western blot analysis and protein identification}

Western blot analysis. The protein samples were separated using 10 and $6 \%$ SDS-PAGE under reducing or non-reducing conditions and stained using Coomassie Brilliant Blue R-250, prior to being transferred onto a polyvinylidene difluoride membrane (Millipore, Billerica, MA, USA) by electroblotting. The rhVEGFR-1 $(1: 50,000)$ was used as the primary antibody and horseradish peroxidase (HRP)-conjugated goat anti-human IgG antibody $(1: 20,000)$ was used as a secondary antibody (BGI-GBI Biotech Co., Ltd., Beijing, China. The Immobilon ${ }^{\mathrm{TM}}$ Western Chemiluminescent HRP Substrate (Millipore) was used to visualize the bound antibody and the final data were recorded using X-Omat BT Film (Kodak, Atlanta, GA, USA).

Protein identification using nanoscale liquid chromatography coupled with tandem high-definition mass spectrometry (nanoLC-HDMS MS/MS). The amino acid sequence of purified rhVEGFR-1 was analyzed using nanoLC-HDMS MS/MS on a nanoACQUITY ${ }^{\mathrm{TM}}$ Ultra Performance LC system (Waters Corp., Milford, MA, USA) and a Synapt HDMS system, with nanospray ion source (Waters Corp.) in the National Center of Biomedical Analysis (Beijing, China).

ELISA. Prior to measuring the association and dissociation constants for the binding of rhVEGFR-1 to VEGF, the affinity was first confirmed using ELISA. A 96-well plate was coated with VEGF-165 and proteins were added to each line with a 1/2-concentration decrement. The maximum molar ratio of each

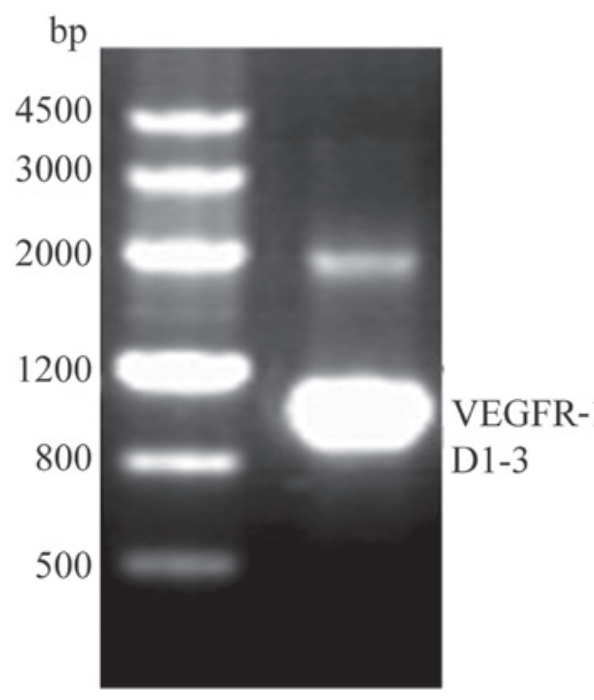

\section{L: Marker R: VEGFR-1 D1-3}

Figure 1. VEGFR-1 cDNA acquired by chemical synthesis. VEGFR-1, vascular endothelial growth factor receptor-1; bp, base pairs.

protein was $\sim 1 / 6$ to the coated VEGF. The plate was incubated at $37^{\circ} \mathrm{C}$ for $1 \mathrm{~h}$ and then the HRP-conjugated goat-anti-human IgG was added $(1: 5,000)$, followed by 3,3',5,5'-tetramethyl benzidine dihydrochloride (Sigma, St. Louis, MO, USA). The plate was then further incubated at $37^{\circ} \mathrm{C}$. The optical density was measured at $450 \mathrm{~nm}$ using an ELISA microplate reader (Bio-Rad, Hercules, CA, USA).

Surface plasmon resonance (SPR) analysis. All procedures were performed using the Biacore 3000 system (Biacore AB, Uppsala, Sweden) in running buffer $(10 \mathrm{mM}$ Tris, $100 \mathrm{mM}$ $\mathrm{NaCl}$ and $0.005 \%$ Tween-80, $\mathrm{pH} 7.5)$ at $25^{\circ} \mathrm{C}$. The VEGF-165 (PeproTech, London, UK) was covalently linked to the carboxylated dextran matrix of the sensor chip CM5 (Biacore AB). Kinetic experiments were performed by injecting a series of concentrations of rhVEGFR-1 (200, 100, 50, 25 and $12.5 \mathrm{nM}$, diluted in running buffer, with or without $10 \mathrm{mM} \mathrm{MgCl}$ ) into the sensor chip CM5. Baselines were regenerated with a 20- $\mu$ l first injection pulse of $10 \mathrm{mM}$ glycine $(\mathrm{pH} 1.5)$ and a second injection pulse of Borate $8.5(10 \mathrm{mM}$ disodium tetraborate and $1 \mathrm{M} \mathrm{NaCl}, \mathrm{pH} 8.5$; Biacore $\mathrm{AB})$, resulting in $<1 \%$ loss of baseline per injection. Dissociation and association rate constants (kd and ka, respectively) were obtained using BIAevaluation 4.0 software (Biacore AB), and the equilibrium dissociation constant, $\mathrm{KD}$, values were calculated by $\mathrm{ka} / \mathrm{kd}$.

Proliferation assay. The proliferation metrics of the human microvascular endothelial cell line HMEC-1, provided by Professor Ding Jian (Shanghai Institute of Materia Medica, Chinese Academy of Sciences, Shanghai, China), were determined by suspending the cells at $2 \times 10^{5}$ cells $/ \mathrm{ml}$ in ice-cold endothelial cell medium (ECM; ScienCell Research Laboratories, Carlsbad, CA, USA) containing all the necessary growth factors and serum supplements. Approximately $50 \mu \mathrm{l}$ cell suspension was seeded into each well of a 96-well tissue culture plate. Upon attachment to bottom of the plate, the ECM was replaced with rhVEGFR-1, ranging between 0 and $800 \mathrm{ng} / \mathrm{ml}$, 


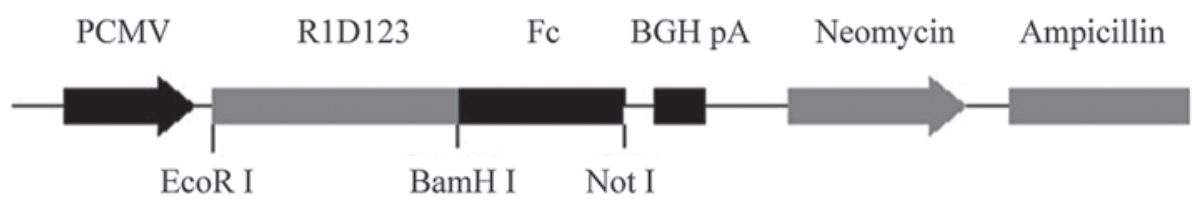

Figure 2. Structure of the expression vector pcDNA3.1-rhVEGFR1D1-3/Fc. The gene was inserted between the EcoR $I$ and Not $I$ restriction enzyme sites. rhVEGFR-1, recombinant human vascular endothelial growth factor receptor-1; PCMV, porcine cytomegalovirus.

and rhVEGF-165 (28 $\mathrm{ng} / \mathrm{ml}$ preincubation) with continuous incubation at $37^{\circ} \mathrm{C}$ under $5 \% \mathrm{CO}_{2}$ for five days. Approximately $50 \mu \mathrm{l} 5 \mu \mathrm{g} / \mathrm{ml}$ Calcein AM (Invitrogen Life Technologies) was then added to each well, and the plate was incubated for an additional 30-60 min under the same conditions. The fluorescence intensities at excitation/emission wavelengths of $485 / 530 \mathrm{~nm}$ were analyzed using a fluorescence plate reader (Thermo Fisher Scientific, Inc., Waltham, MA, USA).

Migration assay. HMEC-1 were suspended in ECM at a density of $4 \times 10^{5}$ cells $/ \mathrm{ml}$. A total of $0.25 \mathrm{ml}$ suspension was placed into a Millicell chamber (Millipore), while $600 \mu \mathrm{l}$ culture medium, containing between 0 and $800 \mathrm{ng} / \mathrm{ml}$ rhVEGFR-1 and rhVEGF-165 (28 $\mathrm{ng} / \mathrm{ml}$ preincubation), was added into the bottom well and incubated at $37^{\circ} \mathrm{C}$ under $5 \% \mathrm{CO}_{2}$ for $12 \mathrm{~h}$. Following incubation, the cells were removed from the top chamber. The insert plate was transferred to another 24-well plate containing $0.5 \mathrm{ml} /$ well Calcein AM (Invitrogen Life Technologies) that was prepared in Hank's Balanced Salt Solution at a concentration of $5 \mu \mathrm{g} / \mathrm{ml}$, and further incubated at $37^{\circ} \mathrm{C}$ under $5 \% \mathrm{CO}_{2}$ for an additional 30-60 min. Migrated HMEC-1 were detected and quantified using a fluorescence plate reader (Thermo Fisher Scientific) with excitation/emission wavelengths of 485/530 nm.

Chorioallantoic membrane (CAM) assay. Fertilized eggs from White Leghorn chickens (Laboratory Animal Center, Beijing, China) were washed with Benzalkonium Bromide $(1: 1,000)$ and incubated blunt-end-up in a standard egg incubator at $37.8 \pm 0.5^{\circ} \mathrm{C}$ and $60-80 \%$ relative humidity. After seven days of development, the eggs to be windowed were dried using $75 \%$ ethanol. An electric engraving tool was used to make a circular window measuring $15-20 \mathrm{~mm}$ in diameter in the air sac. The round shell caps were aseptically removed and the shell membranes were washed with warm, sterile phosphate-buffered saline (PBS). The caps were then completely detached from the shell and the CAM was removed using fine tweezers. Sterile 6-mm-diameter blank concentration disks were first soaked with rhVEGFR-1 (ranging between 0 and $25 \mathrm{pM}$ in $5 \mu \mathrm{l} \mathrm{PBS}$ ) and then aseptically transplanted onto the CAMs. Bovine serum albumin (100 ng) was used as the negative control. Shell windows were then covered with hyalo adhesive tape, and the eggs were further incubated at $37.8 \pm 0.5^{\circ} \mathrm{C}$ and $60-80 \%$ relative humidity. Four days after transplantation, the eggs were fixed in methanol. The CAMs were excised around the disks and images were captured (17).

Directed in vivo angiogenesis assay (DIVAA). The nude mice were subcutaneously implanted with semi-closed silicone cylinders (angioreactors). The angioreactors (DIVAA Inhibition Assay, catalog no. 3450-048-IK) were purchased from Trevigen Inc. (Gaithersburg, MD, USA). Angioreactors
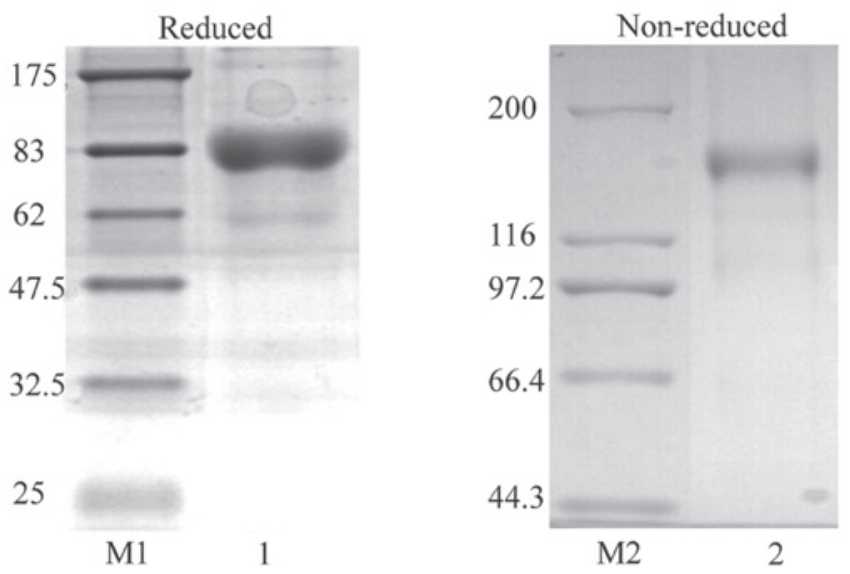

M1,M2: Marker1,2 1,2: hVEGFR1D1-3/Fc in reduced and non-reduced

Figure 3. SDS-PAGE analysis of rhVEGFR1D1-3/Fc. rhVEGFR-1, recombinant human vascular endothelial growth factor receptor-1.

were filled with $18 \mu$ l extracellular matrix premixed with angiogenic or anti-angiogenic factors. The vascularization within the angioreactors was quantified using an intravenous injection of fluorescein isothiocyanate-dextran prior to the recovery of the angioreactor, followed by spectrofluorimetry. The use of immunofluorescence to examine the angioreactors showed the invading angiogenic vessels at different developmental stages. The minimally detectable angiogenic response occurs nine days subsequent to implantation and with the addition of $>50 \mathrm{ng} / \mathrm{ml}$ $(\mathrm{P}<0.01)$ of either fibroblast growth factor- 2 or VEGF. The present study was approved by the Ethics Committee of the Chinese PLA General Hospital (Beijing, China).

Statistical analysis. Statistical analysis was performed using SPSS version 13.0 software (SPSS Inc., Chicago, IL, USA). The data are shown as the means \pm standard error of the mean, and were analyzed by a one-way analysis of variance. A $\mathrm{P}<0.05$ was considered to indicate a statistically significant difference.

\section{Results}

Cloning of rhVEGFR-1. For the cDNA of VEGFR-1, the products on the agarose gels were observed to be $\sim 1,030$-bp long, which was as expected (Fig. 1). The synthesized sequence was then fused with human IgG1Fc (intron included) fragment and cloned into the expression plasmid, resulting in pcDNA3.1-rhVEGFR1 (Fig. 2). Following a 12-day selective culture, the transfected cells formed clones. After a further 12 days, the clones were screened for rhVEGFR-1 using ELISA and confirmed using western blot analysis and peptide sequencing (Fig 3). The evaluation of the inhibitory effect of rhVEGFR-1 was performed by mixing the 
Table I. Effect of $\mathrm{Mg}^{2+}$ on the affinity constant for the binding of rhVEGFR-1 to VEGF-165.

\begin{tabular}{lllll}
\hline $\mathrm{Mg}^{2+}(\mathrm{mM})$ & $\mathrm{ka}(1 / \mathrm{Msec})$ & $\mathrm{kd}(1 / \mathrm{sec})$ & $\mathrm{KA}(1 / \mathrm{M})$ & $\mathrm{KD}(\mathrm{M})$ \\
\hline 0 & $2.60 \times 10^{5}$ & $7.42 \times 10^{-5}$ & $3.5 \times 10^{9}$ & $2.85 \times 10^{-10}$ \\
10 & $1.37 \times 10^{5}$ & $5.07 \times 10^{-5}$ & $2.7 \times 10^{9}$ & $3.71 \times 10^{-10}$ \\
\hline
\end{tabular}

rhVEGFR-1, recombinant human vascular endothelial growth factor receptor-1; VEGF, vascular endothelial growth factor; ka, association rate constant; $\mathrm{kd}$, dissociation rate constant; KA, equilibrium association constant; $\mathrm{KD}$, equilibrium dissociation constant.

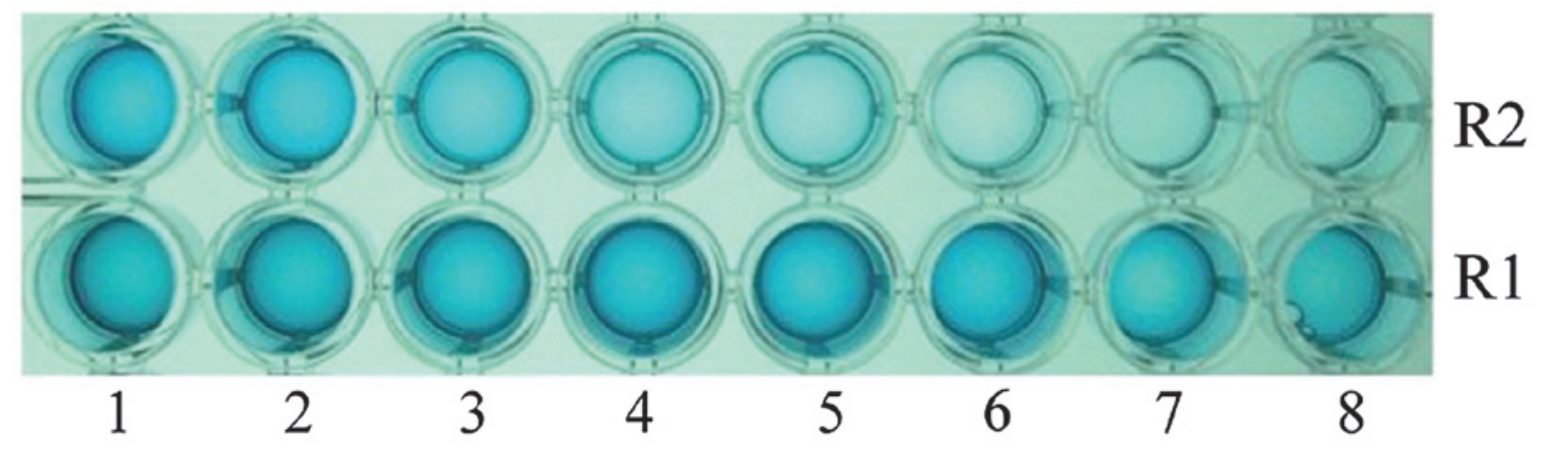

\section{R1: hVEGFR-1, R2:hVEGFR-2.}

Figure 4. rhVEGFR-1 binds to VEGF with higher affinity than rhVEGFR-2. The concentration of each protein decreases from 1 to 8 . rhVEGFR-1, recombinant human vascular endothelial growth factor receptor-1; VEGF, vascular endothelial growth factor.

receptor at concentrations ranging between 0 and $800 \mathrm{ng} / \mathrm{ml}$ with $28 \mathrm{ng} / \mathrm{ml}$ rhVEGF-165 (Table I and Figs. 4 and 5).

rhVEGFR-1 inhibits VEGF-induced HMEC-1 migration. An in vitro assay was performed using HMEC-1 on an angiogenesis cell migration plate. The cells were placed in the top chamber, and the medium containing rhVEGF-165 $(28 \mathrm{ng} / \mathrm{ml})$ premixed with rhVEGFR-1 $(0-800 \mathrm{ng} / \mathrm{ml})$ was added in the bottom chamber. Following incubation for $12 \mathrm{~h}$, rhVEGFR-1 was observed to inhibit the cell migration with a linear correlation at concentrations of 0-200 ng/ml, and the VEGFR-1 binding sites were saturated at the range $200-800 \mathrm{ng} / \mathrm{ml}$ (Fig. 6).

rhVEGFR-1 inhibits CAM angiogenesis. In order to determine the effect of rhVEGFR-1 on angiogenesis, the area of the avascular zone in chicken embryos was analyzed. It was found that it increased in size following the application of rhVEGFR-1 in a dose-dependent manner, confirming the inhibitory effect of rhVEGFR-1 on CAM angiogenesis ( $\mathrm{P}<0.01$; Fig. 7).

rhVEGFR-1 inhibits VEGF-induced angiogenesis in vivo. In an in vivo experiment, angiogenesis was analyzed in nude mice. It was found that rhVEGFR-1 inhibited VEGF-induced angiogenesis in a dose-dependent manner. The application of $160 \mu \mathrm{g} / \mathrm{ml}$ rhVEGFR-1 was shown to almost completely block angiogenesis in nude mice (Fig. 8).

\section{Discussion}

The VEGF pathway is important in the regulation of embryonic vascular development and tumor angiogenesis. Blockade

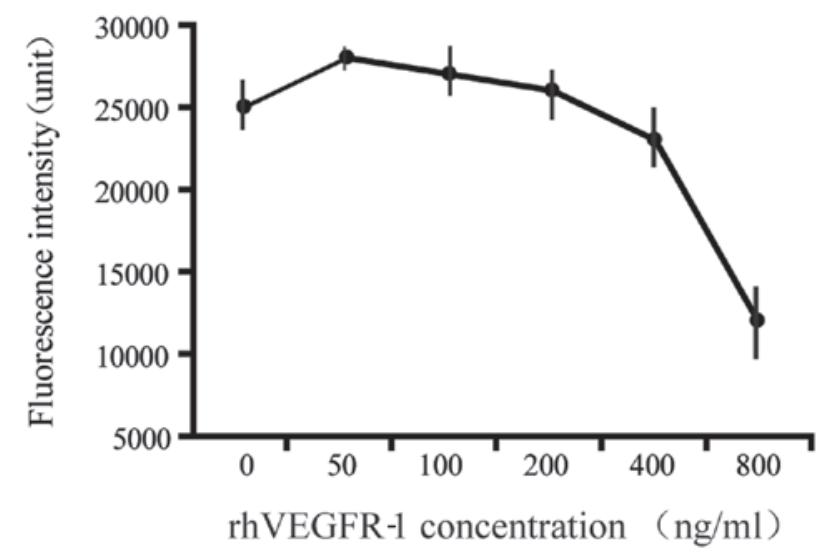

Figure 5. rhVEGFR-1 inhibits HMEC-1 proliferation at concentrations $>200 \mathrm{ng} / \mathrm{ml}$. rhVEGFR-1, recombinant human vascular endothelial growth factor receptor-1.

of the VEGF pathway effectively inhibits tumor angiogenesis and growth in preclinical models. Thus, targeting VEGF may lead to novel therapies for clinical application. Data has also suggested that the potential functional roles of VEGF are associated with its receptors, VEGF1 and VEGF2. The results of the present study suggest that VEGF-121, VEGF-165, VEGF-C and VEGFR-2 may all be involved in regulating carcinoma cell survival, proliferation (via the autocrine signaling mechanism) and migration (via the paracrine signaling mechanism).

The cation $\mathrm{Mg}^{2+}$ is an important supplement in ECM. Notably, it was observed that rhVEGFR-1 bound to VEGF-165 with high affinity without the obvious influence of $\mathrm{Mg}^{2+}$, and the KD value of rhVEGFR-1 binding to VEGF-165 was 


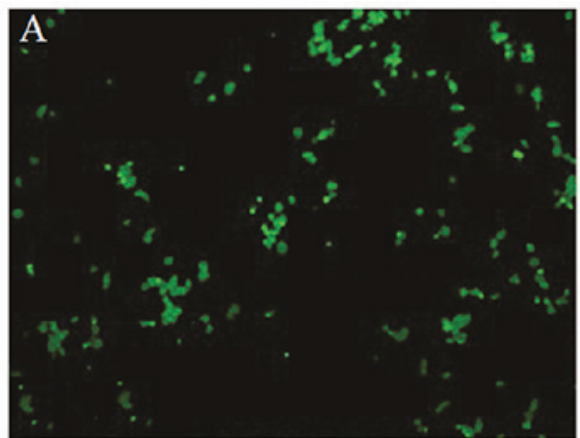

A
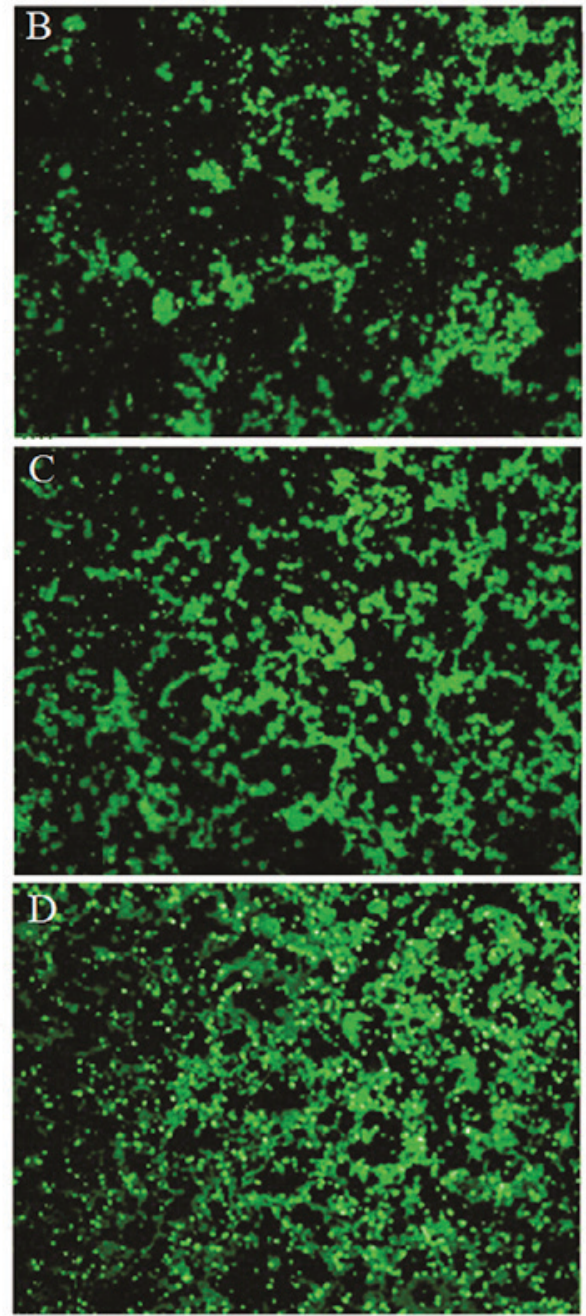

$\mathbf{E}$

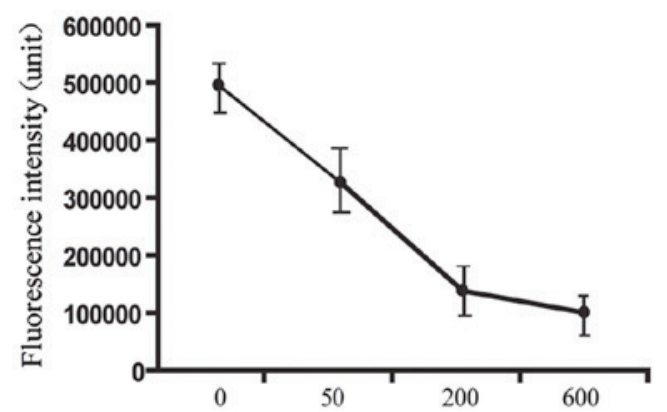

rhVEGFR-1 concentration $(\mathrm{ng} / \mathrm{ml})$

Figure 6. rhVEGFR-1 inhibits HMEC-1 migration. (A) VEGFR-1/Fc $800 \mathrm{ng} / \mathrm{ml}+\mathrm{VEGF} 28 \mathrm{ng} / \mathrm{ml}$. (B) VEGFR-1/Fc $200 \mathrm{ng} / \mathrm{ml}$ + VEGF $28 \mathrm{ng} / \mathrm{ml}$. (C) VEGFR-1/Fc $50 \mathrm{ng} / \mathrm{ml}$ + VEGF $28 \mathrm{ng} / \mathrm{ml}$. (D) VEGF $28 \mathrm{ng} / \mathrm{ml}$. (E) Corresponding statistical results for each group (eight wells). Cell migration markedly decreased $(\mathrm{P}<0.01)$ with increasing concentrations of rhVEGFR-1. rhVEGFR-1, recombinant human vascular endothelial growth factor receptor-1; VEGF, vascular endothelial growth factor.

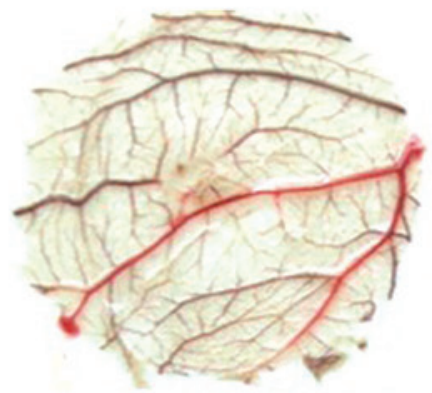

B

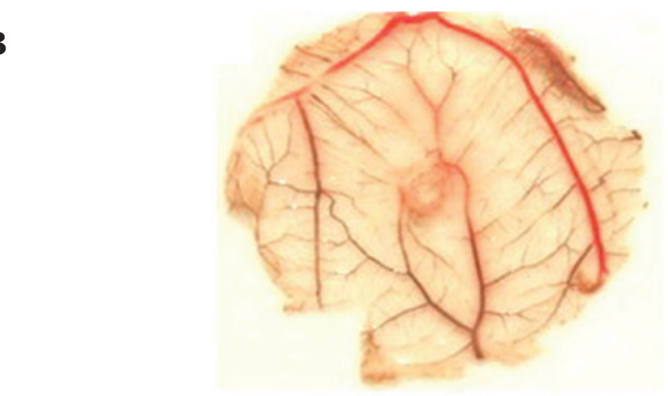

C

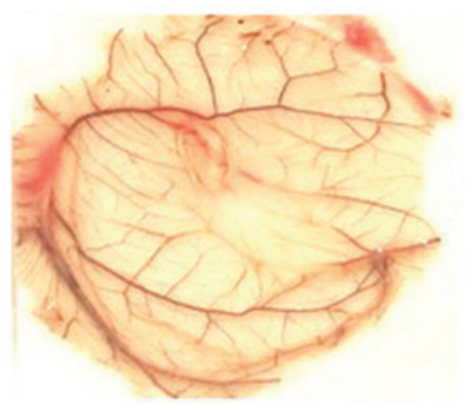

D

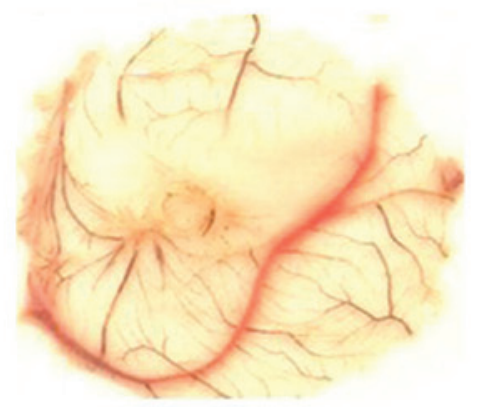

$\mathbf{E}$

D

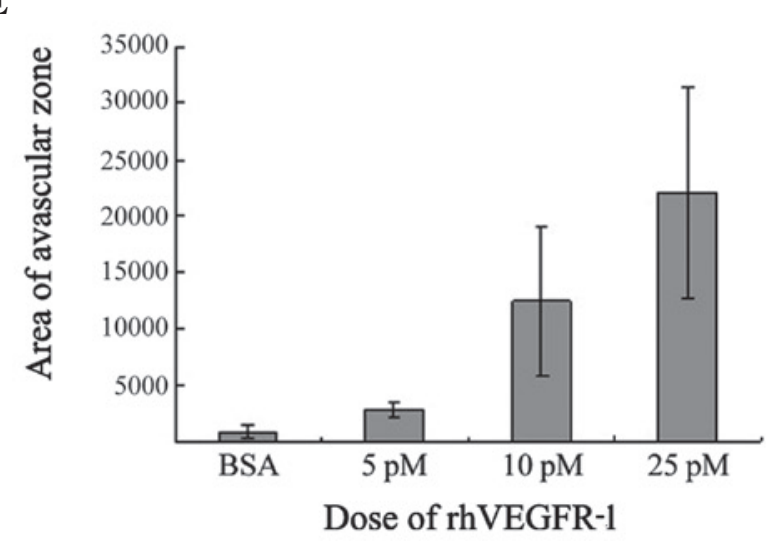

Figure 7. rhVEGFR-1 inhibits chorioallantoic membrane angiogenesis. The area of avascular zone increased with the dose of rhVEGFR-1: (A) $1 \mu \mathrm{g}$ BSA, (B) 5 pM VEGFR-1, (C) 10 pM VEGFR-1 and (D) 25 pM VEGFR-1. (E) Corresponding statistical results for each group (10 eggs). A notable inhibitory effect of rhVEGFR-1 on angiogenesis is shown $(\mathrm{P}<0.01)$. rhVEGFR-1, recombinant human vascular endothelial growth factor receptor-1; BSA, bovine serum albumin. 
A
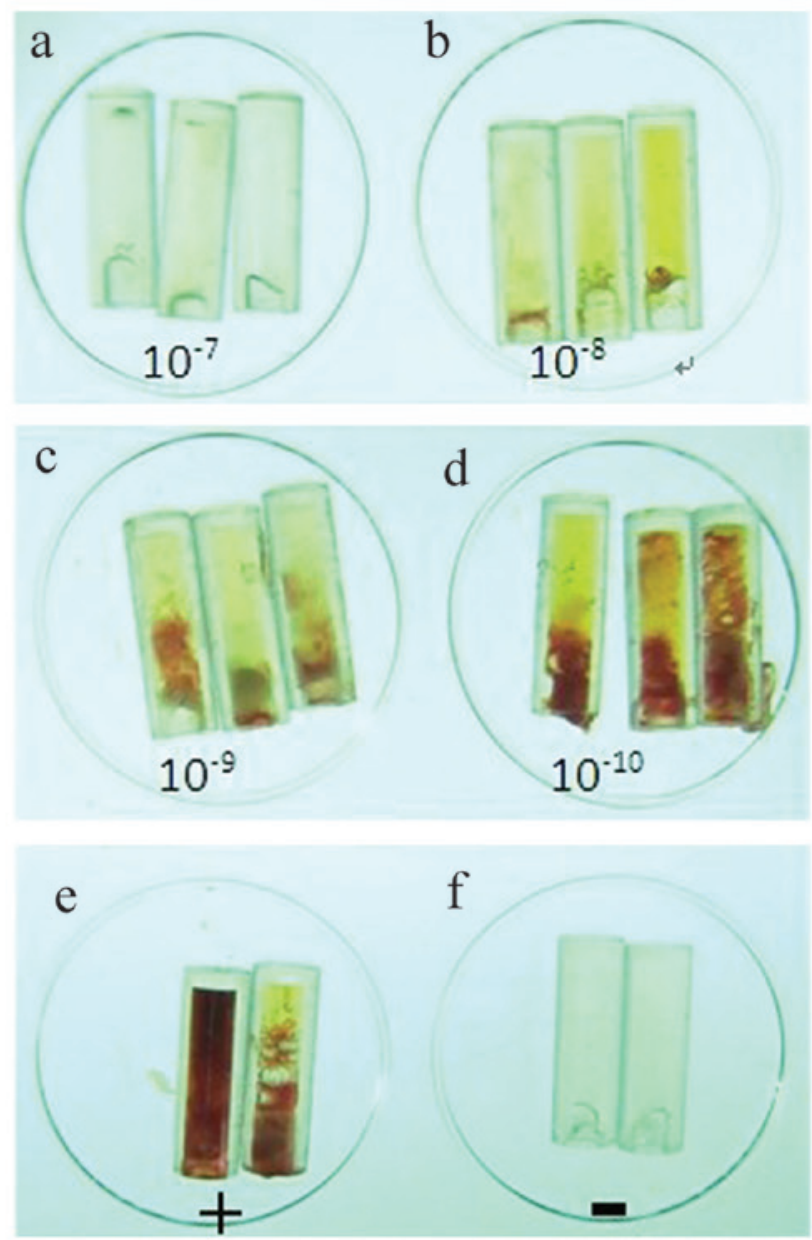

B

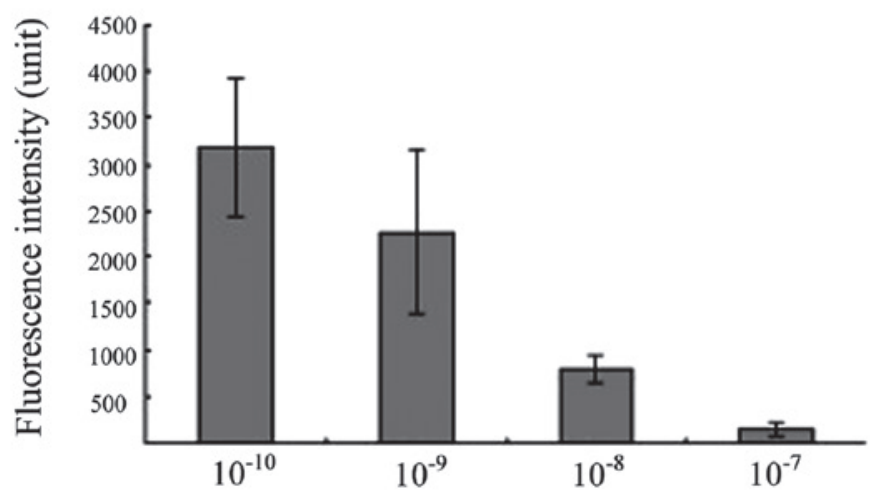

Concentration of rhVEGFR-1 (mol/l)

Figure 8. rhVEGFR-1 inhibits angiogenesis in nude mice. (A) The angioreactors taken from nude mice 12 days after transplantation. The values $1 \times 10^{-7}, 1 \times 10^{-8}$, $1 \times 10^{-9}$ and $1 \times 10^{-10}$ represent the concentration of rhVEGFR-1 (mol/l). (B) Corresponding statistical results for each group. A notable inhibitory effect of rhVEGFR-1 on angiogenesis is shown $(\mathrm{P}<0.01)$. rhVEGFR-1, recombinant human vascular endothelial growth factor receptor-1.

different to that found in previous studies $(13,18,19)$. This may be explained by the fact that the ELISA, Scatchard analysis and ${ }^{125}$ I-VEGF-165 competition analysis employed in previous studies all had multiple steps and may have had poor reproducibility. In the present study, the SPR analysis run on Biacore had just one step and relatively high reproducibility, suggesting that the data from the present study are more reliable.

The dose-effect analysis revealed that rhVEGFR-1 could not block VEGF-165 activity with concentrations $<200 \mathrm{ng} / \mathrm{ml}$. The results suggested a molar ratio of 2:1 of rhVEGFR-1 to homodimeric VEGF-165 to be necessary to reach a minimum inhibition. A ratio of 8:1 appeared to be sufficient for maximum inhibition.

In the in vivo experiment, the DIVAA developed by Guedez et al (20) was found to be extremely sensitive. Without any assistance, newly formed vessels were observed in the angioreactors 12 days subsequent to transplantation.

In conclusion, in the present study an hVEGFR1D1-3/Fc fusion protein was constructed to obtain stable expression in an rCHO cell line. NanoLC-HDMS MS/MS was used to confirm 
the purity of the proteins. The affinity constant for the binding of rhVEGFR-1 to VEGF-165 was determined using SPR for the first time and was found to be accurate. The rhVEGFR-1 showed anti-angiogenic activity in cultured cells, in chicken embryos and in nude mice. The present study demonstrated the important role of VEGFR-1 in regulating VEGF-induced angiogenesis.

\section{References}

1. Leung DW, Cachianes G, Kuang WJ, Goeddel DV and Ferrara N: Vascular endothelial growth factor is a secreted angiogenic mitogen. Science 246: 1306-1309, 1989.

2. Ferrara N, Gerber HP and LeCouter J: The biology of VEGF and its receptors. Nat Med 9: 669-676, 2003.

3. Breen EC: VEGF in biological control. J Cell Biochem 102: 1358-1367, 2007.

4. Carmeliet P: Angiogenesis in health and disease. Nat. Med 9: 653-660, 2003.

5. Carmeliet P: VEGF as a key mediator of angiogenesis in cancer. Oncology 69 (Suppl 3): 4-10, 2005.

6. Clauss M: Molecular biology of the VEGF and the VEGF receptor family. Semin Thromb Hemost 26: 561-569, 2000.

7. Claesson-Welsh L and Welsh M: VEGFA and tumour angiogenesis. J Intern Med 273: 114-127, 2013.

8. Geng L, Chaudhuri A, Talmon G, Wisecarver JL and Wang J: TGF-Beta suppresses VEGFA-mediated angiogenesis in colon cancer metastasis. PLoS One 8: e59918, 2013.

9. Shen K, Ji L, Lu B and Wang Z: c-Jun N-terminal kinase mediated VEGFR2 sustained phosphorylation is critical for VEGFA-induced angiogenesis in vitro and in vivo. Cell Biochem Biophys 64: 17-27, 2012.
10. Weijts BG, Bakker WJ, Cornelissen PW, Liang KH, et al: E2F7 and E2F8 promote angiogenesis through transcriptional activation of VEGFA in cooperation with HIF1. EMBO J 31, 3871-3884, 2012.

11. Shibuya M, Yamaguchi S, Yamane A, Ikeda T, Tojo A, Matsushime $\mathrm{H}$ and Sato $\mathrm{M}$ : Nucleotide sequence and expression of a novel human receptor-type tyrosine kinase gene (flt) closely related to the fms family. Oncogene 5: 519-524, 1990.

12. Terman BI, Carrion ME, Kovacs E, Rasmussen BA, Eddy RL and Shows TB: Identification of a new endothelial cell growth factor receptor tyrosine kinase. Oncogene 6: 1677-1683, 1991

13. Wiesmann C, Fuh G, Christinger HW et al : Crystal structure at 1.7 A resolution of VEGF in complex with domain 2 of the Flt-1 receptor. Cell 91: 695-704, 1997.

14. Park JE, Chen HH, Winer J, Houck KA and Ferrara N: Placenta growth factor. Potentiation of vascular endothelial growth factor bioactivity, in vitro and in vivo, and high affinity binding to Flt-1 but not to Flk-1/KDR. J Biol Chem 269: 25646-25654, 1994.

15. Ejima D, Yumioka R, Tsumoto K and Arakawa T: Effective elution of antibodies by arginine and arginine derivatives in affnity column chromatography. Anal Biochem 345: 250-257, 2005.

16. Arakawa T, Philo JS, Tsumoto K, et al: Elution of antibodies from a Protein-A column by aqueous arginine solutions. Protein Expr Purif 36: 244-248, 2004.

17. Shi ML, Duan HF, Xu ZP, Hu XW and Chen HP: Optimization of applying chick chorioallantoic membrane to angiogenesis assay. Letters in Biotech 19: 566-568, 2008 (In Chinese).

18. Herley MT, Yu Y, Whitney RG and Sato JD: Characterization of the VEGF binding site on the Flt-1 receptor. Biochem Biophys Res Commun 262: 731-738, 1999.

19. Holash J, Davis S, Papadopoulos N, et al: VEGF-Trap: a VEGF blocker with potent antitumor effects. Proc Natl Acad Sci USA 99: 11393-11398, 2002.

20. Guedez L, Rivera AM, Salloum R, et al: Quantitative assessment of angiogenic response by the directed in vivo angiogenesis assay. Am J Pathol 162: 1431-1439, 2003. 